\title{
O DISCURSO JURÍDICO NA OBRA SENHORA DE JOSÉ DE ALENCAR
}

\author{
Josele da Rocha Monteiro'
}

\begin{abstract}
RESUMO
Partindo do ponto que, para entender um texto literário, uma compreensão do contexto extralinguístico é necessária, é possível perceber que o texto literário de José de Alencar em sua obra "Senhora " está inserido no universo jurídico, em outras palavras, os temas relacionados neste livro são considerados uma verdade distante para aqueles que não pertencem ao campo da lei, transformando a narrativa em um texto de difícil compreensão para os leitores leigo-jurídico.Com base nas questões acima mencionadas, os leitores podem observar as instituições jurídicas da família serem discutidas e analisadas ao longo da leitura de"' Senhora, uma vez que essas questões revelam as verdadeiras intenções de José de Alencar, o autor da obra. Concluindo, é notável que há um estreito vínculo entre a Literatura e o Direito ao lidar com esta obra e um claro entendimento sobre as questões jurídicas representam a materialização de tal argumento.
\end{abstract}

Palavras-chave: Literatura, Direito, Instituições Jurídicas, Texto Literário.

ABSTRACT

Starting from the point that to understand a literary text, an understanding of the extralinguistic context is required, it is possible to realize that the literary text of José de Alencar in his writing "Senhora" is inserted in the Law universe, in other words, the topics related in this book are considered a distant truth for the ones who do not belong to the Law field, turning the narrative into a difficult text to comprehend for layman.Based on the above mentioned issues, readers can observe the Legal Family Institutions being discussed and analysed along the reading of "Senhora" once those topics reveal the great and trully intention of José de Alencar, the author.Concluding, it is noted that there is a strait bonding between Literature and Law when dealing with this book and a clear understanding about those juridical issues represent the materialization of such argument.

key-words: Literature, Law, Juridical Institutions, Literary Text.

\section{INTRODUÇÃO}

Felizmente, alguns grandes nomes da Literatura Brasileira que se tem notícia possuem formação jurídica, razão pela qual se justifica a herança de uma linguagem polida e bem estruturada. É claro que existiu todo um contexto histórico-político para que todos fossem bacharéis em Direito, mas é inegável tal legado e a dívida imensurável para com tais homens das letras. Autor?

Infelizmente, parece que a tradição se perdeu no decorrer do tempo, pois hoje poucos são os bacharéis, advogados, enfim, os operadores do direito que conseguem articular bem nossa língua

\footnotetext{
${ }^{1}$ Mestrando Ciência da Educação pela Facultad Interamerciana de Ciencias Sociales. Contato: joselermonteiro@gmail.com
} 
materna, deixando muito a desejar em suas exposições orais, muitas vezes na escrita, quando algum procedimento assim os exige.

Apesar da crítica inaugural, o foco deste estudo não se refere à análise do emprego correto ou não da língua materna nos discursos jurídicos, mas analisar, a partir de um texto literário, o discurso jurídico ali presente.

Como dito anteriormente, os grandes nomes da literatura brasileira são de origem acadêmico-jurídica e por tal vivência seus textos estão impregnados de sutis traços jurídicos que para um leigo na Ciência do Direito passaria de forma despercebida. Ocorre que, se um jurista fizer uma leitura mais apurada, atenta, perceptível, verificará desde os mais simples diálogos entre as personagens ou na fala do narrador a utilização de elementos jurídicos.

Neste sentido, com intuito de introduzir nos cursos jurídicos a rememoração dos clássicos da literatura brasileira, este artigo analisará os traços jurídicos contidos na obra Senhora, do escritor cearense José de Alencar, considerado o grande nome do romantismo brasileiro.

A motivação determinante para a realização deste estudo é a percepção obtida de que a maioria dos leitores sejam estes juristas ou não encontram grande dificuldade em compreender os romances clássicos brasileiros e tal limitação está intimamente ligada ao conhecimento dos institutos jurídicos presentes em tais obras.

Não se descarta, porém, que a linguagem utilizada em 1875, data em que foi escrita a obra Senhora, seja muito mais rebuscada e refinada em relação à utilizada em 2010, constituindo-se, assim, a própria linguagem um óbice ao entendimento.

Este artigo tem por finalidade identificar todos os elementos jurídicos presentes na obra selecionada, conceituando-os e assim proporcionar uma contextualização de tais conhecimentos jurídicos como chaves para uma leitura mais clara e precisa do romance.

Convém mencionar a razão pela qual se deu a escolha de uma obra de José de Alencar ano??. A razão é simplista, tendo em vista o fato de este autor ter sido o pioneiro para a construção de uma identidade nacional até então inexistente, pois a independência não foi capaz de por si construir uma ideologia nacional.

Destaca-se ainda ter sido José de Alencar o primeiro a escrever de forma independente da literatura herdada de Portugal. A independência de linguagem e estruturas fizeram de Alencar o símbolo da luta da construção de uma literatura realmente brasileira. Sua linguagem rebuscada revelava o tom do homem da alta sociedade que era, deixando claro todo o seu conservadorismo em relação aos valores apregoados, mas estes mesmos valores serviriam de base para as mais duras críticas em seus romances. 
Após sua fase indianista, Alencar passa, em seus romances urbanos, a analisar a decadente sociedade carioca em que está, socialmente, inserida a obra Senhora. Na busca de materiais a respeito de Alencar, pouco há que se encontrar. Entretanto, a escassez de material não diminui sua relevância para a literatura, visto que, em se tratando da vastidão de suas obras, tal autor é considerado o maior escritor da literatura nacional, acompanhado de seu sucessor Machado de Assis ano, maior expoente do movimento realista brasileiro.

Este estudo possui pilar metodológica sendo uma revisão de cunho bibliográfico partindo do problema relatado a partir das referencias teóricas cientificas publicas em documentos, nesse modo busca-se estudar e analisar teorias cientifica do assunto relacionado, tornando-se objeto essencial para estudos monográficos científicos, embasada a partir de teóricos renomados e especialistas em José de Alencar e em literatura brasileira, como Bosi, Massaud Moisés, teóricos jurídicos e outras fontes que serão detalhadas ao longo do estudo a ser apresentado em seguida.

\section{ALENCAR, O DIREITO E AS LETRAS}

Cearense de nascimento e carioca de coração, José Martiniano de Alencar, nasceu em 01 de maio de 1829. Estudou Direito em São Paulo, e parte em Olinda e, assim como seu pai, tomou gostou pela luta política, galgando, assim, posição junto à política brasileira: foi Deputado, Senador e Ministro da Justiça do Segundo Reinado.

Pouco se fala das suas produções jurídicas não devido a questões ligadas à qualidade do texto, mas seu maior expoente foi o pioneirismo do romance brasileiro ao revelar nossos costumes e símbolos. $\mathrm{Na}$ verdade, com Alencar, foi idealizado o índio como sendo o maior símbolo nacional, justificando a trilogia de sua fase indianista: Iracema, O Guarani e Ubirajara.

Seguindo a tendência criada por ele mesmo - a de trilogias temáticas -, Alencar cria uma nova modalidade de romance - o Romance Urbano. Nessa modalidade, o marco da literatura brasileira advém da trilogia com o perfil feminino, imortalizado nas figuras de Aurélia Camargo, Lucíola e Emília, a diva.

Apesar de possuir outros romances urbanos como A Viuvinha e Cinco Minutos, as obras Senhora, Diva e Lucíola são as que mais caracterizam o perfil da mulher urbana do fim do século XIX do Rio Janeiro. Naquele momento, o Rio de Janeiro não é apenas a capital do Império de D. Pedro II, mas também a capital literária brasileira.

Dessa trilogia romancista apresentada, é objeto de estudo, neste artigo, a figura de Aurélia Camargo, protagonista da obra Senhora. 


\section{CONTEXTO JURÍDICO DA OBRA}

Ao escrever o romance "Senhora", Alencar, criterioso como era, deu para cada capítulo títulos compostos por termos jurídicos os quais estruturam a narrativa da obra. Esses termos, se observados por um leigo na operação da técnica jurídica, não fazem muito sentido e, em via de consequência, não interferem na compreensão do texto. Porém, se analisados por um técnico, ou seja, por alguém com apurado olhar jurídico, os títulos passam a transmitir toda a essência da narrativa descrita ao longo da narrativa.

Dessa forma, mais uma vez destaca-se que nenhum escritor consegue fugir de sua essência maior, que é a sua formação originária. Assim, nesta obra de forma particular, os institutos jurídicos concentram os detalhes mais relevantes e decisivos do enredo romântico.

Objetivando dar aos títulos nomes que por si só seriam capazes de transmitir uma sequência lógica e dar movimento ao enredo, Alencar estruturou a obra com a seguinte disposição: a) O preço; b) A quitação; c) A posse; e d) $O$ resgate.

Se observados com um olhar técnico-jurídico e não apenas do ponto de vista literário, a conclusão a que se chega é que tais títulos retratam de forma objetiva os elementos que constituem o Instituto dos Contratos, pois, via de regra, ressalvadas todas as exceções possíveis, todo contrato inicia-se logo depois de selecionado o objeto de interesse e a discussão do preço.

Depois de selecionado o objeto e estabelecido o valor a ser pago, passa-se a discussão da posse da "coisa" adquirida, lembrando sempre que, para ser objeto de contrato, a "coisa" deve estar disponível no mercado e ter, por esta razão, valor comercial.

É conhecimento jurídico geral que, depois de feita a quitação, ou seja, depois de pago o valor, é possível reclamar a posse que, de forma voluntária, será dada ao adquirente do objeto ou, de forma judicial, por meio de algum instrumento legal que de forma contenciosa possa satisfazer tal pretensão, a exemplo da imissão na posse.

Poucos são os contratos que trazem em seu texto a possibilidade de resgate da "coisa" em data posterior, sem a necessidade de uma nova negociação e ajuste de novos valores e reinserção da posse anteriormente perdida pela tradição do bem, quando móvel, ou do registro, em se tratando de bens imóveis.

Tais títulos inseridos em um romance podem causar certa perplexidade ao leitor mesmo após a explanação do contexto jurídico de aplicação destes termos em seu sentido prático. Todavia é salutar informar que os romances urbanos, no qual se insere a obra Senhora, tem por finalidade questionar e 
atacar a artificialidade dos hábitos e valores da sociedade decadente do Império de D. Pedro II. Entende-se, neste momento, que o foco de análise é a sociedade burguesa, a saber, os frequentadores da corte e dos nobres salões fluminenses.

Menciona-se que o instituto mais criticado por Alencar, nesta obra de forma específica, é o casamento, pois este era regulado por um conjunto de normas imbuídas de sentido totalmente masculinizado, a saber, machista, reflexo da sociedade patriarcal daquele período da história do direito brasileiro.

Dentro deste contexto, a mulher era considera um ser relativamente capaz, ou seja, para que seus atos fossem válidos frente às relações jurídicas pactuadas na sociedade, era necessária a anuência manifestada de seu representante legal. Neste sentido, a mulher, até então submetida ao pátrio poder de seu pai, agora se submetia ao poder marital.

O sistema jurídico ainda estabelecia que o casamento fosse um negócio jurídico entre as famílias, devendo os chefes destas instituições, formularem entre si de forma verbal, um pacto de casamento futuro. Dentre as previsões dadas ao casamento, destaca-se a ideia jurídica expressa em lei a qual dizia que, após o casamento, o marido teria o prazo de 10 dias para anular o casamento, se constatasse que sua esposa não fosse virgem ao tempo da cerimônia. Isso porque a virgindade, naquele contexto, era a expressão máxima da honra não apenas da noiva, mas também de sua família.

Neste contexto, justifica-se o surgimento de muitos cabarés na cidade imperial, formado por moças que possuíam conhecimentos musicais, dançavam com esmero e falavam outras línguas, pois tais mulheres eram as enjeitadas por serem desonradas e abandonadas à própria sorte pelas famílias tradicionais.

O dote era o maior atrativo para os noivos, pois este simbolizava, por alguma razão, ser um bom partido para o cargo de marido. Assim, muitos casamentos de conveniência eram firmados, deixando de lado todo o aspecto sentimental deste instituto.

Destaca-se que a única forma de constituição de família, naquele período, era por meio do matrimônio e nenhuma outra forma de construção de entidade familiar era reconhecida ou tutelada pelo direito brasileiro e português.

Desta realidade, surge um adágio popular que diz: "O amor nasce com o tempo, com a convivência." Tal adágio era a justificativa para um casamento que trouxesse segurança econômica e projeção social, ou seja, um bom nome de família e um bom patrimônio eram razões suficientes para um ajuste matrimonial indissolúvel de acordo com a norma influenciada pela Igreja. 
Por se tratar de uma crítica social, Alencar, na obra Senhora, inverte os valores, os papéis e com suas personagens desfocadas dos seus papéis originais, critica de forma veemente a submissão da mulher e seu papel na sociedade artificial e decadente carioca e dos casamentos aparentes.

\section{O PREÇO}

Este capítulo inicia-se de forma a não despertar no leitor qualquer indício ou suspeita do seu real sentindo ou finalidade maior. O preço refere-se à compra de um marido falido, pobre, mas de boa aparência, chamado Fernando Seixas.

E assim inaugura Alencar o texto: "há muitos anos raiou no céu fluminense uma nova estrela" (ALENCAR, 1875, p.15).

A referência é Aurélia Camargo, até então desconhecida da alta sociedade. Aqui há uma crítica muito sutil, pois a obra e o capítulo relatam a história de uma moça com traços finos, de comportamento nobre, mas de origem é humilde. A "nobre" Senhora foi costureira e padeceu das maiores adversidades, além de viver à margem da sociedade, fadada a um casamento que não the rendesse nenhuma perspectiva de um futuro diferente de seu presente.

Neste capítulo, é apresentada ao leitor uma mulher diferente daquela descrita na norma jurídica. Aqui se apresenta uma mulher forte, senhora de si e de muitos escravos.

Esta mulher era o perfil, na verdade, ansiado das mulheres de seu tempo. É importante informar que o público consumidor de romances e de livros, em sentido geral, eram as mulheres burguesas e ociosas, ou seja, com poucos afazeres domésticos (RIBEIRO, 2008, p.51).

Aurélia, por ser mulher e não deter o direito à direção de sua família (que se resumia a ela, seu tio, uma parenta que era sua ama de companhia e o seu vasto patrimônio, herdado de forma universal de seu avô paterno), utiliza-se da figura de seu tutor (seu tio Lemos) para conseguir um bom partido para casar; mas esta já tem definido quem seria seu futuro marido e o preço a ser pago pela compra deste constataria em uma escritura pública.

Aqui se concentra uma das maiores críticas de Alencar, pois, neste ponto, as mulheres se veem vingadas, porque, se antes estas eram o objeto de compra do casamento por meio do dote, agora é uma mulher quem dá o preço, escolhe o objeto a ser comprado e a forma de pagamento.

A mulher aqui apresentada é a oposição total do sistema jurídico-social da época. Nesta obra, Alencar inaugura uma discussão indireta da independência e representatividade feminina tanto social como jurídica. 
Contactado o futuro marido, ajustado o preço e sendo dado por este seu aceite, é firmado entre Lemos, representante da noiva, e Fernando Seixas, o marido comprado, um contrato verbal e uma promessa de futuro casamento.

\section{A QUITAÇÃO}

Seguindo a ideia de um negócio jurídico contratual, chega o momento da quitação, ou seja, o momento do pagamento do valor ajustado e os esclarecimentos, agora, do papel a ser desempenhado pelo marido comprado e pela esposa que passa a ser chamada pelo marido de Senhora. Ou seja, fica claro e evidente que a esposa, deste momento em diante (após a quitação do marido), passa a ocupar o posto que pertencesse ao homem.

Na noite de núpcias, Aurélia informa a seu marido a natureza do negócio celebrado entre eles, o que até então, pensava Fernando, ser desconhecido da esposa os detalhes em relação à transação realizada.

Assim, Aurélia diz que tudo até aquela noite era parte de um plano para fazer com que Fernando se sentisse como ela se sentiu ao ser abandonada por ele na adolescência por ser pobre, por não poder oferecer a ele um dote interessante e uma posição nos salões da corte carioca.

Neste momento, a esposa vingada entrega a seu marido um cheque administrativo com o valor restante a ser pago por seu dote e passa a tratá-lo como uma "coisa", uma parte de seu patrimônio.

Em uma de suas falas, Aurélia diz que comprou o marido por uma simples razão: o casamento é um sacrifício necessário às moças de boa conduta, ou seja, estas se casam por uma necessidade social. Aurélia ainda informa ao marido que ele é como uma "coisa" e como tal estava disponível no mercado e, por estar no mercado, tinha preço e foi adquirido por ela e agora pode ser chamado de "Meu marido!" (ALENCAR, 1875, p.122).

Alencar torna público por meio de seu texto toda a artificialidade dos casamentos daquele período, bem como a infelicidade e insatisfação da mulher com seu papel na sociedade, agora reinventado em Aurélia e, acima de tudo, a fragilidade dos laços matrimoniais firmados mediante uma contraprestação pecuniária.

\section{A POSSE}

Uma vez pactuada a compra de determinada "coisa", ajustado seu valor e feita a quitação é possível ao titular de sua propriedade reclamar sua posse, ou seja, nada e ninguém podem, de forma legítima, opor-se à tomada, uso e possessão do objeto. 
Em se tratando de coisa imóvel ou móvel, juridicamente falando, bastaria uma medida de imissão na posse para que o titular pudesse ser imitido para desfrutar daquilo que fosse de direito seu.

Ao analisar este enfoque jurídico, observa-se que seriam passíveis de tais medidas apenas coisas, objeto pactuado, e não um ser humano, pois nenhuma pessoa está disponível no mercado para ser objeto de compra e a legislação não trata de tal possibilidade.

Aqui reside outra crítica Alencariana, que é a redução do homem à condição de objeto jurídico de compra por meio do casamento, ou seja, via de regra, em sua maioria, o casamento era uma espécie de compra pré-ajustada entre os chefes das famílias com total anuência da sociedade e submissão feminina, "coisificando"-se, assim, o homem.

O casamento passava a ser o maior projeto de vida de toda mulher, mas a mulher não poderia em regra escolher seu próprio marido; este era selecionado por seu pai ou representante legal. Outro aspecto da figura feminina em relação ao casamento era que, com a ocorrência deste, a mulher tornava-se, incondicionalmente, submissa ao seu marido, senhora do lar. Ou seja, se no exterior do seu lar, a mulher permanecia sem muita expressividade, no interior, na vida privada, todos os escravos e serviçais tinham missão diária a cumprir e fazer outros cumprirem as ordens da senhora daquela casa. No lar e nas questões relativas à sua organização e educação dos filhos, a mulher era absoluta e senhora de todos.

\section{O RESGATE}

Mesmo imbuída de crítica à sociedade e inovações polêmicas no comportamento de suas personagens, Alencar sempre foi um homem conservador e por tal ideologia o romance Senhora não poderia ter um fim que agredisse de forma geral ao senso comum estabelecido até então. Autor? Desta forma, Alencar apresenta o desfecho do romance com a redenção do marido comprado e a submissão da esposa altiva.

Após a quitação, Fernando passa a rever seu comportamento, seus valores e ações.

Neste sentido, começa a trabalhar como todo homem médio, a cumprir uma carga horária de trabalho estabelecida, a viver de seu salário de funcionário público, a utilizar transporte público em vez de fazer uso do carro particular da família (ALENCAR, 1875, p.146).

Ao se deparar com seu estado de "coisa comprada", Fernando Seixas, homem até então pobre, sem fortuna herdada e estudos superiores, decide resgatar sua dignidade (acima de tudo, por se tratar de um ato de compra) e liberdade. Ambas simbolizavam o resgate da escritura pública, firmada entre os noivos dias antes do casamento. 
Assim, Fernando de marido comprado, homem interesseiro e inescrupuloso, torna-se um funcionário exemplar, homem caseiro. Os presentes comprados por Aurélia como o enxoval do noivo permaneceu intacto até seu efetivo resgate. Tal enxoval era composto por ternos e trajes de passeio de fino corte, perfumes de aromas europeus, joias, móveis de escritório charutos cubanos, etc.

Abdicar desse mundo de conforto, antes tão ansiado por ele, foi o marco inicial da redenção que culmina com a devolução do valor do dote pago por Aurélia ao tempo do ajuste do casamento. Neste momento, Aurélia restitui a dignidade e a liberdade de seu marido e entrega-Ihe a escritura pública pactuada para o casamento.

\section{OS INSTITUTOS JURÍDICOS:}

\subsection{REGIME DE BENS}

É conveniente, antes de tratar do texto de Alencar, conceituar o instituto do regime de bens.

Assim conceitua o estudioso Carlos Roberto Gonçalves (2010; p.4 20):

É o conjunto de regras que disciplina as relações econômicas dos cônjuges, quer entre si, quer no tocante a terceiros, durante o casamento. Regula especialmente o domínio e a administração de ambos ou de cada um sobre os bens anteriores e os adquiridos na constância da união conjugal.

Neste mesmo sentido, assente Maria Berenice Dias ao afirmar que os regimes de bens configuram a expressão máxima do princípio da solidariedade estabelecido com o matrimônio, em que marido e mulher tornam-se responsáveis por todos os custos ou encargos relacionados à família (2007; p. 200).

Dentro do contexto da novela, Alencar destaca com clareza que o regime de casamento entre Fernando e Aurélia será o da separação de bens. O autor ainda destaca, no próprio texto, que tal opção se deu pelo fato da noiva ser, ao tempo do casamento, relativamente incapaz, pois, naquele período, a maioridade civil era atingida aos 21 anos e Aurélia contava apenas com 18 anos. Tal pensamento jurídico ainda é predominante, conforme expressa o dispositivo 1641 do vigente Código Civil.

O discurso jurídico, nesta parte obra, foi absorvido também pelo legislado civilista de 1916, pois foi estabelecido no Código Civil revogado que a maioridade civil se atingia aos 21 anos, conforme expressava o art.9 do referido documento legal.

Para os leitores sem qualquer informação jurídica, a leitura dessa parte do romance, que remonta aos ajustes do casamento arranjado entre Fernando e Aurélia pelo tutor desta, mais parece um embuste da protagonista com vista a proteger seu patrimônio. Mas para os operadores do direito e os estudantes mais afincos de José de Alencar, tal detalhe não passa de forma despercebida, visto que, 
sendo este autor um conservador nato, não poderia escrever algo que fosse contrário ao sistema jurídico vigente.

É importante destacar que os romances urbanos de Alencar configuram uma ferramenta de alta crítica à sociedade decadente do Segundo Império Brasileiro. Por esta razão, a intenção do autor é fazer refletir a respeito de questões inerentes aos valores sociais praticados, e não de atacar os sistemas jurídicos, pois, como já foi informado, Alencar era um jurista e político de formação e por descendência.

Desta forma, justificado está o fato de o regime de casamento entre Fernando Seixas e Aurélia Camargo ter sido o da separação obrigatória de bens. Isso o impossibilitava, inclusive, o acesso no momento de arrecadar herança ou herdar pela sucessão legítima qualquer bem de sua esposa, por constituir a chamada sanção civil, atualmente prevista no art. 1641 do Código Civil de 2002, instituído pela Lei 10046/02.

\subsection{TUTELA}

Criado com a intenção de proteger aqueles que estavam à margem da sociedade e da família, tutelar alguém significar responder pelo mesmo, cuidar, proteger, respaldar.

De acordo com os estudos de GONÇALVES (2010; p.623), tutela "é o encargo conferido por lei a uma pessoa capaz para cuidar da pessoa menor e administrar seus bens."

No mesmo sentido, Caio Mário (2009; p. 443) ratifica a idéia anterior ao dispor no texto de sua obra que a tutela:

Consiste no encargo ou múnus conferidos a alguém para que dirija a pessoa e administre os bens do menor de idade que não incide no poder familiar do pai ou mãe. Este, normalmente, incorre na tutela, quando os pais são falecidos ou ausentes, ou decaíram da pátria potestas.

Em Senhora, a tutela se manifesta logo no início da obra ao apresentar o Sr. Lemos como o tio e tutor da jovem Aurélia. A função de Lemos é gerir os negócios, o patrimônio e a vida civil de sua sobrinha e pupila.

Um aspecto interessante na obra é a fidelidade ao Direito, que mais uma vez merece destaque, agora sendo enfocado na escolha do tutor. Segundo o texto literário, a escolha se faz por meio de um testamento deixado pelo avô paterno de Aurélia. Neste aspecto, Alencar se ateve nos mínimos detalhes ao texto jurídico vigente, que estabelecia que a tutela poderia ser determinada por ato de última vontade, a saber, o testamento.

Tal entendimento foi reproduzido no Código Civil de 1916, hoje revogado, bem como no Codex de 2002, conforme transcrição abaixo: 


\section{Art.1729 (caput)}

Parágrafo único. A nomeação deve constar de testamento ou de qualquer outro documento autêntico.

Outro detalhe que não pode passar em branco é o fato da escolha do tio para tutor. Segundo a norma de 1916/2002, a preferência é sempre da família originária do pupilo, sem deixar, é claro, de ser observado o aspecto da afetividade tão bem inserida na tutela do vigente Código.

Lemos é tio de Aurélia e mantém com ela uma relação de total cumplicidade. Aurélia é uma moça que, apesar de sua pouca idade, é de personalidade forte e determinada e consegue com tais traços de personalidade manipular seu representante jurídico para que sua vontade, ao fim, seja feita sem soar como tirana ou insoberba.

Lemos, por sua vez, sabe de seu papel e de sua responsabilidade. Alencar destaca no texto de forma precisa e objetiva que este sabe que, ao casar-se, Aurélia deixaria de estar sob sua responsabilidade jurídica, pois o casamento era uma forma ou ponte para que a mulher ingressasse na sociedade e passasse a ser chamada senhora de sua casa e família.

\subsection{TESTAMENTO E DO RECONHECIMENTO DE PATERNIDADE}

Considerado como sendo o último registro da vontade de alguém ainda vivo, o testamento sempre foi, no sistema jurídico brasileiro, o guardador de segredos e, por vezes, de enormes reviravoltas no meio ambiente familiar.

A família Camargo é surpreendida com a última disposição de vontade de seu patriarca ao reconhecer a paternidade de um filho já falecido, mas que havia deixado esposa e dois filhos.

$\mathrm{Na}$ ficção literária, ao tempo da abertura da sucessão do patriarca dos Camargo, dois fatos jurídicos e relevantes mudam toda a condução do romance: o primeiro fato é a pré-morte do pai de Aurélia, que já era falecido ao tempo da morte do avô da protagonista de Alencar. Com tal morte, Alencar lança mão de um instituto jurídico para resolver o impasse que poderia ser estabelecido naquele momento, pois sem o reconhecimento da paternidade de seu pai, Aurélia não poderia reclamar para si nenhum status de herdeira deste.

Neste sentido, o instituto da representação ou sucessão por estirpe estabelece que, na ausência por morte do herdeiro legítimo direto a ser chamado, o seu sucessor, provando a sua condição pode reclamar para si o quinhão que caberia a seu ascendente por fazer parte da mesma linhagem deste.

Para amarrar bem o texto sem que houvesse por parte do autor qualquer infidelidade ao disposto na norma, Alencar informa que o Sr. Camargo, certa vez, dirigiu-se ao cartório de registro civil e reconheceu por meio de uma escritura pública a paternidade do pai de Aurélia e informa que 
reconhecia a moça como sendo filha de seu filho, ou seja, sua neta e herdeira de todo o seu patrimônio, constituindo-se nesta a figura de herdeira universal de toda sua fortuna.

Importante aqui se faz a explicação da possibilidade de reconhecimento de paternidade por meio de escritura pública era uma realidade estabelecida no então revogado Código Civil de 1916, em seu art.357.

Em corroboração a tal ideologia, o atual sistema civilista estabelece no art. 1609 que:

O reconhecimento dos filhos havidos fora do casamento é irrevogável e será feito:

[...] II - Por escritura pública ou escrito particular, a ser arquivado em cartório; [...]

O segundo fato que marca e muda todo o rumo da história da protagonista é a morte prematura de sua mãe e do seu irmão, que, segundo o autor, este padecia de um retardo mental.

Um lapso temporal transcorre entre a morte da mãe e do irmão de Aurélia até o falecimento de avô, mas Alencar não deixa expresso no texto a mensuração deste espaço. Alencar apenas informa que, tempos mais tarde, Aurélia compreende a omissão de seu avô em prestar ajuda a ela e sua mãe recém enlutadas pela morte do neto e sem qualquer condição financeira de manutenção, pois Aurélia e sua mãe trabalhavam como costureiras para as famílias da corte.

\subsection{HERANÇA}

Considera-se como sendo herança todo o conjunto de bens materiais ou imateriais pertencentes à determinada pessoa que se transmite após a sua morte aos seus herdeiros estabelecidos pela lei, sem deixar de fazer parte dessa massa patrimonial as suas dívidas.

Menciona-se que, em se tratando das dívidas deixadas, a responsabilidade civil dos herdeiros se limita ao quinhão hereditário recebido, ou seja, dívidas superiores ao valor da herança não alcançam o patrimônio particular dos herdeiros.

Neste sentido, por um jogo de nomenclaturas jurídicas, aquele que recebe a herança passa a ser chamado de herdeiro e assim sendo uma única pessoa existente ao tempo da abertura da sucessão, além de ser nominado herdeiro universal, torna-se o único indivíduo, de forma universal, a ser titular de todo o patrimônio do autor da herança. 


\subsection{REGIME DOTAL}

Como mencionado anteriormente, o sistema jurídico vigente refletia com precisão a sociedade da época, totalmente ruralista e machista. Neste aspecto, além da devolução da esposa por defloramento, existia para os homens um atrativo para contrair matrimônio: o dote.

No Brasil, diferente dos países do Oriente Médio, onde o marido é o devedor do dote como demonstrativo de que este possui condições suficientes para o sustento da nova família que se constituirá com o casamento, era a família da noiva que era a responsável pelo pagamento do dote como garantia do futuro enlace.

Após a Constituição de 1988, não havia como se manter tal previsão, visto que a isonomia entre homem e mulher estava estabelecida no art. 5 da $\mathrm{CF} / 88$, bem como o fim do sentido patriarcal atribuída ao pátrio poder e chefia da família por parte do homem.

$\mathrm{Na}$ obra de Alencar analisada neste artigo, o tutor de Aurélia, Sr. Lemos, informa ao noivo que a noiva está disposta a pagar 100 contos de réis pelo casamento. $O$ autor deixa claro em seu texto que, sem saber de quem se tratava, sem revelar a identidade da noiva e apenas informando algo superficial sobre seu aspecto, Fernando Seixas aceita se casar com a desconhecida simplesmente pelo dote atrativo.

Conforme o enredo, Lemos informa que o regime matrimonial de bens a ser aplicado é o da Separação de Bens. Neste momento da obra, um leitor sem a formação originária jurídica não compreende a razão para que tal regime passa a reger o casamento.

Segundo previa a norma do código civil já revogado, mas repetido no atual sistema jurídico civil vigente, aquele que se casa com quem necessita de consentimento para o casamento, a este casal será aplicado, na vigência do matrimônio, o regime da separação obrigatória de bens, conforme prescreve o artigo 1641 do Código Civil.

Tal modalidade de regime além de tornar incomunicável o patrimônio constituído antes e durante a constância matrimonial impede sucessão do cônjuge sobrevivente no patrimônio deixado pelo outro. No texto Alencar, de forma sutil, apenas se informa por meio do personagem Lemos que tudo não passa de uma exigência do juizado de órfãos e sucessões, mas não são tecidos comentários que deixem claro a realidade legal enrustida nesta informação, passando este detalhe importante como simplesmente uma parte da trama. 


\subsection{ESPONSAIS}

De pouca discussão jurídica até $1988 \mathrm{com}$ tal nomenclatura, o instituto dos esponsais ganha espaço quando se discute o dano moral decorrente do rompimento danoso de um compromisso futuro de casamento.

No direito brasileiro, nem mesmo no Código Civil de 1916 existia um dispositivo que tratava de forma específica a respeito do tema; bem como no de 2002 não há um dispositivo nominado com tal nomenclatura, mas sim uma aplicação abrangente do art.186, que trata da base da responsabilização civil e ainda da reparação do dano moral, advindo de uma ação ou omissão ou imperícia no comportamento do agente causador do dano.

Atento ao seu tempo jurídico, Alencar não insere essa discussão, mas menciona apenas um comportamento que poderia gerar se existisse ao menos o debate teórico do tema naquele período. O comportamento referido na obra é o rompimento injustificado do noivado celebrado entre Fernando Seixas e Adelaide do Amaral.

Menciona-se que, antes de aceitar a proposta do tutor de Aurélia, Fernando Seixas havia firmado para com o pai de Adelaide e perante sua família o compromisso de um casamento futuro, selando tal compromisso por meio do noivado. Se tal comportamento fosse analisado à luz do sistema jurídico vigente, certamente Fernando Seixas poderia, se comprovados os fatos e o constrangimento moral, responder por danos à jovem Adelaide.

$\mathrm{Na}$ época em que os fatos da ficção são narrados, a mulher abandonada ficava mal vista pela sociedade e, dificilmente, casar-se-ia futuramente. Preocupado com o efeito negativo de tal desfazimento, Alencar trata de dar um desfecho feliz para a jovem, mas para isso, mais uma vez a protagonista, considerada agora senhora do destino de todos que a cercavam, encontra para esta um homem que não seria apenas um bom partido para marido conforme sua época, mas também um homem apaixonado e disposto a fazê-la feliz.

Por não existir na época a possibilidade de reparação de danos pelo desfazimento lesivo do noivado ou compromisso de casamento futuro, não se indenizava ou não se condenava por não amar o suficiente para se casar e com isso ligar sua vida definitivamente à outra pessoa.

\subsection{DIVÓRCIO (MOTIVO PELO QUAL FERNANDO E AURÉLIA NÃO SE DEIXARAM)}

Alguns leitores poderiam questionar a razão pela qual Fernando Seixas e Aurélia Camargo seguem em um casamento marcado pela humilhação constante, discussões e ofensas sucessivas. 
Por se tratar de uma obra pertencente ao período romântico, o amor dos protagonistas está acima das diferenças, dos erros do passado e das adversidades do presente.

O autor sabia da inexistência da possibilidade do instituto do divórcio que tanto se conhece hoje como forma de se pôr fim ao casamento, pois o Brasil só conheceu essa possibilidade a partir de 1977 por meio da Lei 6515/77.

Desta forma, para não fugir nem ao sistema jurídico conservador vigente nem perder a característica romântica, Alencar redime os protagonistas e tanto um quanto outro celebram entre si o perdão, demonstrando assim, no fim da obra, que os relacionamentos são baseados na tolerância mútua, ou seja, em uma relação de onde os envolvidos devem ceder para manter vivo o sentimento compartilhado.

Adotar o divórcio na obra seria um escândalo social e jurídico e como conservador que era Alencar não compraria briga com a igreja com intuito de defender talvez uma nova ideologia jurídica anunciada quase cem anos de sua incorporação ao sistema jurídico.

\section{CONSIDERAÇÕES FINAIS}

Percebe-se, por fim, que além de ser atencioso ao texto polido, bem escrito e formalmente bem construído à guisa da língua pátria, José de Alencar, em seu texto, não fugiu as suas origens jurídicas, empregando na obra Senhora de forma correta cada um dos mencionados e conceituados institutos jurídicos. Ainda é relevante mencionar que, mesmo sendo uma fiç̧ão, ou seja, algo que não corresponde à realidade dos fatos, Alencar foi fiel ao sistema jurídico vigente. Por esta razão, é de suma relevância a leitura deste clássico do Romantismo Brasileiro para se compreender bem a aplicação dos institutos jurídicos do direito de família. Em muitos casos, Literatura e Direito sempre estiveram juntos e o movimento do romantismo é prova real de tal afirmativa.

A análise aqui feita restringiu-se, apenas, a uma obra de Alencar, mas tal novela conseguiu, em sua construção textual, englobar grande parte dos institutos do direito de família, tutelado pelo ordenamento jurídico daquele e deste tempo. Este artigo é uma ferramenta eficiente para uma melhor compreensão tanto do texto literário como do texto jurídico vigente ao tempo da construção do romance, bem como do atual, pois a comparação dos sistemas jurídicos se torna inevitável.

\section{REFERÊNCIAS}

ALENCAR, José de. Senhora. 3 ed.São Paulo: Martin Claret, 2009.

BRASIL, Lei 10406 de 11 de janeiro de 2002 - Código Civil, 2010. São Paulo: Manole, 2002. 
DIAS, Maria Berenice. Manual de direito das famílias. 4 ed., São Paulo: Revista dos Tribunais, 2007.

GONÇALVES, Carlos Roberto. Curso de Direito Civil Brasileiro. V.6.7 ed., São Paulo: Saraiva, 2010.

PEREIRA, Caio Mario da. Curso de Direito Civil Brasileiro. V. Ed., São Paulo: Saraiva, 2008.

RIBEIRO, Luis Filipe. Mulheres de papel. 2 ed. São Paulo: Forense Universitária, 2008.

VIANA FILHO, Luís. A vida de José de Alencar. 2 ed. São Paulo: UNESP, 2008. 